\title{
KEANEKARAGAMAN ANGGREK ALAM DAN KEBERADAAN MIKORIZA ANGGREK DI DUSUN TURGO PAKEM, SLEMAN YOGYAKARTA
}

\section{THE DIVERSITY OF ORCHID MYCORRHIZA EXISTENCE IN TURGO VILLAGE PAKEM, SLEMAN YOGYAKARTA}

\author{
Lili Sugiyarto *, Siti Umniyatie dan Victoria Henuhili \\ Jurusan Pendidikan Biologi, FMIPA, Universitas Negeri Yogyakarta \\ *email: victoria_henuhili@uny.ac.id
}

Diterima 2 Agustus 2016 disetujui 5 September 2016

\begin{abstract}
Abstrak
Penelitian ini bertujuan untuk melihat keanekaragaman, mikoriza simbion, dan keberadaan mikoriza di akar anggrek alam di Dusun Turgo Pakem Yogyakarta. Metode yang digunakan dengan mengidentifikasi jenis anggrek, mengisolasi dan mengkarakterisasi fungi mikoriza adalah media PDA (potato dextrose agar) yang dilanjutkan dengan identifikasi setiap fungi yang diperoleh. Pengukuran faktor lingkungan abiotik meliputi faktor edafik yaitu kelembaban, $\mathrm{pH}$, suhu tanah, dan mikroklimat yaitu suhu udara, kelembaban udara, dan intensitas cahaya. Infeksi mikoriza diamati dengan mengamati keberadaan fungi pada jaringan akar. Hasil pengamatan menunjukkan adanya 8 spesies anggrek alam yaitu : Zeuxine petakinensis, endrobium sagittatum, Bulbophyllum chaetonium, Dendrobium mutabile, Eria retusa, Eria oblitterata, Pholidota carnea, Rhomboda velutina. Beberapa anggrek spesies di hutan tersebut dalam keadaan dorman sehingga tidak dapat diidentifikasi. Keberadaan mikoriza dari hasil pengamatan mikroskopis menunjukkan bahwa pada umumnya akar anggrek spesies yang ditemui berasosiasi simbiose dengan mikoriza yang masing-masing menunjukkan jenis fungi yang berbeda. Fungi yang dapat didentifikasi diantaranya termasuk dalam genus Rhizoctonia, Glomus, Chaetonium, Scopulariopsis dan Trichoderma Kata kunci: spesies anggrek, mikoriza, fungi anggrek
\end{abstract}

\begin{abstract}
This research aims to identify the diversity of orchids and to find the existence of mycorrrhizal symbiont in wild orchid roots in Turgo village, Pakem Sleman. The samples of orchids and orchid roots were done by taking samples in Puspa Forest of Turgo Village, Pakem Sleman Yogyakarta. This research were exploration research on existing orchids' diversity. The methods that have been used to identify the existing orchid species in the forest, isolation, and characterization mycorrhizal fungi is PDA (potato dextrose agar). Measurement of environmental factors for including edhapic factors were humidity, pH, soil temperature, and microclimate factors were air temperature, air humidity, and light intensity. The mycorrhizal infection was done by observing of mycorrhizal fungi existence. The results of the research are retrieved 8 species of orchids are Zeuxine petakinensis, Dendrobium sagittatum, Bulbophyllum chaetonium, Dendrobium mutabile, Eria retusa, Eria oblitterata, Pholidota carnea, Rhomboda velutina. Some orchids in the forest are dormant, therefore it couldn't be identified. The mycorrhizal symbiosis from microscopic characterization had been known as different on each mychorriza. The mycorrhizal fungi that have been identified were genus of Rhizoctonia, Glomus, Chaetonium, Scopulariopsis and Trichoderma.
\end{abstract}

Keywords: orchid species, mychorrhiza, orchid fungi

\section{Pendahuluan}

Anggrek merupakan salah satu tanaman hias berbunga yang banyak disukai. Di Indonesia hampir di semua pulau mempunyai anggrek alam yang spesifik. Keanekaragaman anggrek di Indonesia sangat menguntungkan sebagai sumber genetik untuk menghasilkan silangan-silangan baru yang memberikan ciri khas Indonesia. Dari sekitar 5000 jenis anggrek spesies Indonesia, baru sebagian kecil saja yang dapat dimanfaatkan untuk pengembangan anggrek di Indonesia. Hal ini karena kurangnya pengenalan akan jenis-jenis anggrek alam dan kurangnya koordinasi dari instansi yang terkait yang bergerak dalam pemanfaatan kekayaan alam Indonesia. 
Anggrek dalam sistematika tumbuhan termasuk familia Orchidaceae yang mempunyai lebih dari 800 genera dan paling sedikit 3000 spesies, ditambah dengan hibrida hasil silangan yang semakin bertambah dari tahun ke tahun [1]. Anggrek merupakan tanaman berbetuk herba, seringkali hidup secara terrestrik, epifitik atau saprofitik. Mempunyai akar rimpang (rhizome) atau akar yang berdaging, akar menempel, akar menggantung, akar berkarang dan umbi akar.

Orang menanam anggrek pasti dengan tujuan untuk menikmati bunganya. Bunga anggrek memang sangat menarik, terutama bunga hasil silangan. Bunga hasil silangan biasanya mempunyai sifat-sifat yang disukai oleh banyak penggemar bunga anggrek. Sifat-sifat tersebut antara lain warna bunga, corak bunga, bentuk bunga, dan terutama adalah sifat bunga yang tidak cepat layu sebagai bunga potong maupun bunga di pot. Hasil silangan tanaman anggrek diperoleh dari keturunan induk spesies alam yang ada di Indonesia. Bunga anggrek spesies alam mempunyai sifat yang cukup menarik baik warna, corak, bentuk maupun ukurannya. Beberapa bunga spesies anggrek alam mengeluarkan bau yang harum. Kelemahan anggrek alam adalah banyak yang bunganya tidak tahan lama mekar, tetapi mempunyai kelebihan lain dalam sifat, misalnya mempunyai corak bunga yang khas atau bentuk bunga yang spesifik tidak ada di tempat lain. Walaupun demikian banyak juga anggrek alam yang mempunyai ketahanan mekar cukup lama, bahkan ada yang sampai beberapa bulan.

Pada akar tanaman anggrek terdapat mikorhiza yang biasanya bersimbiose dengan tanaman anggrek melalui akarnya. Fungi mikoriza mengambil zat organik dari humus mengubahnya dan kemudian diberikan kepada anggrek, sedangkan anggrek memberikan hasil asimilasinya kepada fungi. Interaksi dua organisme yang saling menguntungkan. Fungi yang hidup berdampingan ini tidak bersifat patogen, walaupun pada tanaman yang lain fungi ini mungkin bersifat parasit. Fungi yang hidup sebagai mikoriza beraneka-ragam, mungkin berbeda antara spesies satu dengan lainnya, tergantung juga dengan faktor lingkungan dimana akar itu berada dan kemungkinan fungi itu dapat beradaptasi dengan lingkungannya. Keberadaan mikoriza pada jaringan akar juga diamati untuk mengetahui sejauh mana mikoriza menginfeksi jaringan akar.

Akar anggrek terutama yang epifit, diselubungi velamen, yaitu lapisan sel berdaging yang berperan dalam penyerapan dan penyimpanan air [2] kemudian dibawa ke batang dan daun sukulen yang mempunyai stomata kriptopor yang dapat mencegah terjadinya transpirasi dan evaporasi dari jaringan kortikal [3]. Air dan nutrient yang larut di dalamnya seperti sulfat, fosfat, nitrat dan senyawa lainnya diserap melalui ujung akar berwarna hijau, yang merupakan sel aktif dan selalu membelah [4].

Lenz dan Wimber menyebutkan bahwa biji anggrek mempunyai wujud sangat kecil dan tidak mempunyai endosperm, sehingga perkecambahan secara alamiah tidak dapat terjadi kecuali bila biji sudah terifeksi fungi mikoriza, atau yang pada awal pertumbuhannya ada invasi oleh fungi ke dalam biji yang kemudian akan memberikan makanan pada awal pertumbuhan kecambah muda [5].

Tidak terdapatnya endosperm (cadangan makanan) pada biji anggrek disebabkan karena tidak terjadinya peleburan antara inti sperma dengan inti polar, atau karena selalu terjadi degenerasi setelah bersatunya inti sperma kedua dengan dua inti polar yang menghasilkan inti triploid. Pada beberapa tanaman, sebelum mengalami degenerasi, inti triploid masih mengadakan beberapa kali pembelahan walaupun tidak akan terbentuk endosperm yang sempurna. Keadaan ini dapat dilihat pada Paphiopedilum insigne (2 sel), Polystachia geraensis (4 sel), Bletilla striata (8 sel) dan Vanilla planifolia (10 sel) $[3,6]$.

Kebanyakan tanaman berbunga sering terjadi adanya invasi dari sejenis cendawan yang hidup bersimbiosis di dalam akar. Hubungan simbiosis ini tidak merugikan pertumbuhan anggrek tetapi bahkan memberikan manfaat bagi tanaman yang bersangkutan. Akar yang terinfeksi cendawan tersebut akan berubah struktur morfologinya menjadi bentuk yang spesifik, yang disebut mikoriza [7].

Pada anggrek, mikoriza umumnya merupakan anggota dari genus Ceratobasidium, Sebacina, dan Tulasnella [8]. Cendawan ini sangat penting pada awal kehidupan anggrek, karena adanya aktifitas selulolitik dari cendawan endofitik yang dapat mengubah selulosa di dalam tanah menjadi senyawa nutrisi yang diserap oleh cendawan dan kemudian dimanfaatkan oleh anggrek [6].

Senyawa nutrisi yang diberikan oleh fungi mikoriza antara lain gula, vitamin, asam amino dan senyawa lain yang belum dapat diidentifikasi. Selain itu juga niasin yang dihasilkan oleh Rhizoctonia sp. yaitu vitamin yang dapat mempercepat perkecambahan dan pertumbuhan bibit anggrek [3]. Perkecambahan dengan bantuan kerjasama fungi ini, bila terjadi dimana spesies 
anggrek ini tumbuh pada habitatnya yang asli, akan melestarikan kelangsungan hidup spesies anggrek yang bersangkutan, sehingga spesies asli yang bermanfaat sebagai tanaman induk tidak akan lenyap dan punah.

Di Indonesia banyak spesies anggrek alam yang berpotensi sebagai tanaman induk. Misalnya tetua spesies alam dari Dendrobium yang menurunkan warna kuning yaitu $D$. goldii [9], D. undulatum, D. schulleri [10], D. spectabile [11]. Pada Phalaenopsis, untuk mendapatkan hibrida berwarna kuning dipergunakan induk silangan $P$. amboinensis var kuning [12]. Jenis-jenis Vanda spesies alam Indonesia yang banyak dipakai sebagai induk silangan antara lain $V$. sumatrana, $V$. tricolor, dan V. pumila [13].

Penyeleksian tanaman anggrek alam baik dari Indonesia maupun dari luar Indonesia bertujuan antara lain untuk mengumpulkan tanaman yang mempunyai sifat unggul untuk dijadikan tanaman induk [10]. Seleksi populasi pada spesies yang sama dimaksudkan juga untuk memilih populasi yang kemampuan ekspresi gennya atau kelompok gen-gen yang diinginkan maksimal. Setiap spesies memiliki macam dan jumlah gen yang sama. Walaupun demikian, tidak semua anggota atau individu dalam spesies tersebut mampu mengekspresikan semua gen yang dimiliki [14].

Artikel ini menguraikan tentang tingkat keanekaragaman anggrek alam dan keberadaan mikoriza simbion pada setiap anggrek di Hutan Puspa, Dusun Turgo,Pakem Sleman Yogyakarta.

\section{Metode Penelitian}

Jenis penelitian ini adalah penelitian eksploratif tentang keanekaragaman anggrek dan mikoriza simbion yang terkait. Pengamatan dan pengambilan sampel akar anggrek di Hutan Puspa yang berlokasi di Dusun Turgo, Desa Purwobinangun, Pakem, Sleman. Pengamatan fungi mikoriza di Laboratorium Mikrobiologi Jurdik Biologi FMIPA UNY. Waktu penelitian dilakukan dari bulan Juni-Oktober 2015.

Parameter yang diamati pada penelitian ini meliputi: keanekaragaman anggrek yang terdapat di Hutan Puspa Dusun Turgo, Purwobinangun, Pakem, Sleman; genus mikoriza dan infeksi mikorizanya.

Sampel anggrek diambil secara acak di Hutan Puspa Dusun Turgo, Purwobinangun, Pakem, Sleman meliputi anggrek terestrial dan anggrek epifit. Pengambilan akar anggrek terestrial dilakukan dengan hati-hati supaya mendapatkan akar utuh. Pengambilan akar anggrek epifit dilakukan dengan cara mengambil tanaman anggrek yang menempel di pohon Puspa pada ketinggian antara 1-10 meter dari permukaan tanah.

Tanaman anggrek dan akarnya dimasukkan ke dalam plastik klip diberi label nama atau kode nama tanaman, kemudian dimasukkan kedalam ice box untuk menjaga kesegaran anggrek selama perjalanan menuju laboratorium. Akar anggrek terpilih kemudian dibersihkan dengan air mengalir, kemudian dipotong $\pm 10 \mathrm{~cm}$ dari ujung akar. Akar anggrek kemudian disayat secara melintang setipis mungkin dan diletakkan di atas gelas benda dan ditetesi dengan larutan pewarna metilen biru $0,05 \%$. Sayatan akar anggrek diamati di bawah mikroskop cahaya. Keberadaan jamur mikoriza berupa peloton yaitu hifa yang menggulung memenuhi sel akan tercat metilen biru.

Akar anggrek yang sudah diketahui terdapat mikoriza kemudian diisolasi jamur mikorizanya dengan cara sebelumnya dicuci terlebih dahulu dengan air mengalir selama 10 menit, setelah itu dipotong akar sepanjang $\pm 1 \mathrm{~cm}$, direndam dalam alkohol $70 \%$ selama 3 menit, klorox $5 \%$ selama 5 menit, kemudian dicuci dengan akuades steril 3 kali. Akar anggrek selanjutnya dipotong membujur, dan diletakkan pada medium PDA (Potato Dextrose Agar) dengan bagian dalamnya menempel pada media.

Inkubasi dilakukan selama 3-5 hari hingga hifa jamur tumbuh. Koloni yang tumbuh disekitar akar, kemudian dipindah pada media PDA miring untuk memperoleh kultur murni dan selanjutnya dipindah ke media PDA pada petridish diameter $5 \mathrm{~cm}$ untuk pengamatan makroskopis meliputi pertumbuhan koloni, warna koloni, warna sebalik koloni, formasi sklerotia, exudate drop (tetes air), keberadaan hifa aerial, radial furrow, zonasi, tekstur koloni, permukaan koloni, growing zone (zona tumbuh) dan diameter koloni selama 14 hari [5].

Pengamatan mikroskopis meliputi ada tidaknya sekat pada hifa, ada tidaknya alat tambahan pada hifa, diameter hifa, bentuk percabangan sel hifa, bentuk spora atau konidia, bentuk sporangium atau konidiofor [15] [16].

\section{Hasil dan Pembahasan}

Hasil pengamatan anggrek alam yang terdapat di hutan Puspa menunjukkan adanya 2 anggrek terestrial, yaitu Zeuxine petakinensi dan Rhomboda velutina. Yang ditemukan lainnya adalah anggrek epifit, yaitu Dendrobium sagittatum, Bulbophyllum flavescens, Dendrobium mutabile, Eria retusa, 
Pholidota carnea. Penelitian ini dilaksanakan pada musim kemarau sehingga terdapat beberapa tanaman anggrek dalam keadaan dorman dan ada yang hanya satu tanaman di lokasi hutan tersebut pada waktu pengambilan sampel, seperti anggrek terestrial Zeuxine petakinensi, sehingga tidak dapat dipakai sebagai sampel mengetahui mikoriza simbionnya.

Pada akar anggrek Rhomboda velutina berhasil diisolasi satu kandidat mikoriza dengan ciri-ciri makroskopis sebagai berikut: warna koloni coklat, warna sebalik coklat muda hingga coklat tua. Koloni membentuk lingkaran-lingkaran konsentris gelap terang (coklat tua dan coklat muda). Pigmen hifa Rhizoctonia umumnya bervariasi dengan warna utama coklat koloni muda pada media buatan biasanya berwarna putih, tetapi dengan bertambahnya umur warna koloni menjadi coklat tua. Beberapa ada yang tetap berwarna putih atau berpigmen lainnya tetapi tetap memiliki variasi corak berwarna coklat. Permukaan koloni flat, tekstur kapas, tidak mempunyai zonasi,

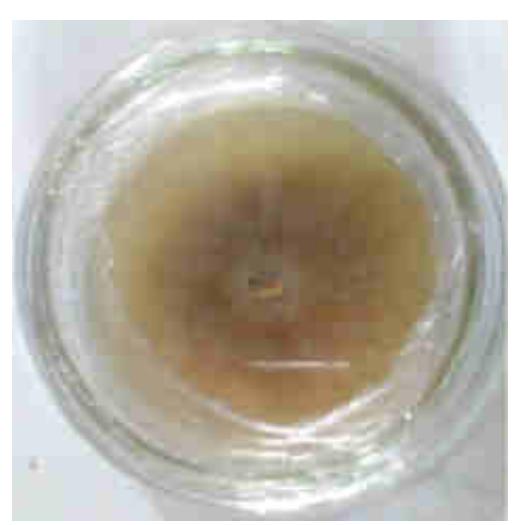

(A)

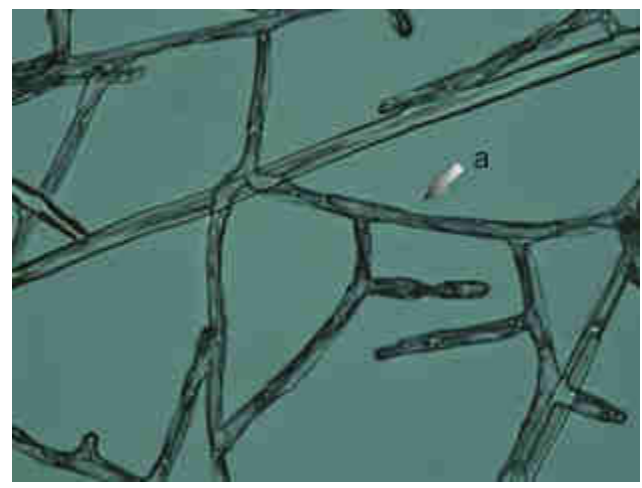

(C) mempunyai growing zone, tidak mempunyai radial furrow, koloni tidak mengeluarkan tetes eksudat dan tidak ada sklerotia. Kandidat mikoriza tersebut mempunyai ciri-ciri mikroskopis sebagai berikut: hifa bersekat, berwarna coklat dan membentuk miniloid dan tdk membentuk clamp connection, konidium dan rhizomorf. Memiliki 2 inti sehingga termasuk dalam binukleat. Kandidat mikoriza ini merupakan golongan Rhizoctonia (Gambar 1).

Pada akar anggrek Dendrobium sagittatum berhasil diisolasi satu kandidat mikoriza yang memiliki ciri-ciri makroskopis sebagai berikut: warna permukaan koloni putih, permukaan cembung, warna sebalik koloni putih kecoklatan, tekstur kapas, tidak mempunyai zonasi dan tidak mempunyai radial furrow, tetes eksudat, sklerotia tetapi memiliki growing zone. Kandidat mikoriza tersebut mempunyai ciri-ciri mikroskopis sebagai berikut: hifa tidak bersekat dan berspora. Kandidat mikoriza ini merupakan golongan Scopulariopsis (Gambar 2).

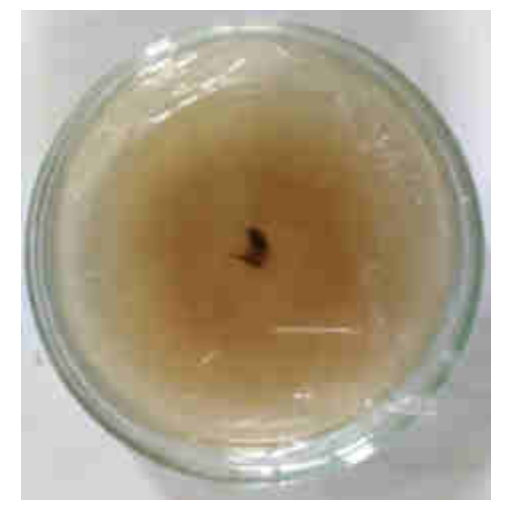

(B)

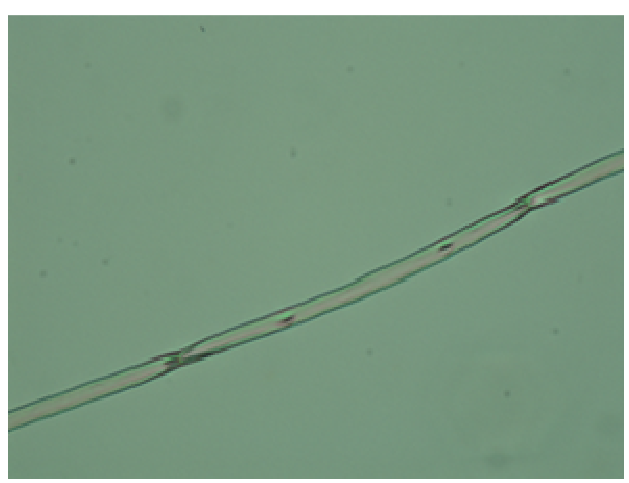

(D)

Gambar 1. Pengamatan Mikroskopis Kandidat Mikoriza pada Rhomboda velutina.(A). koloni mikoriza tampak atas, (B). koloni mikoriza tampak bawah, (C). (a) hifa bersekat, (b) miniloid dan (D). binukleat 


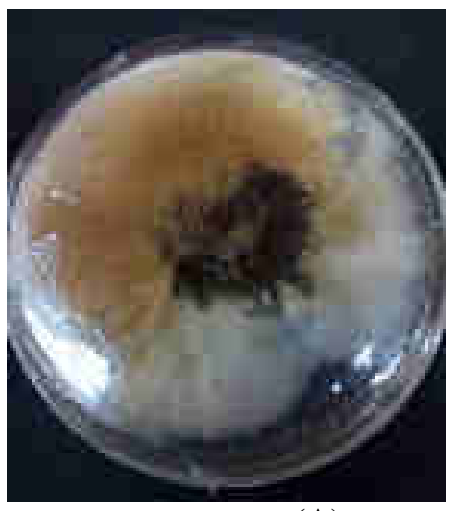

(A)

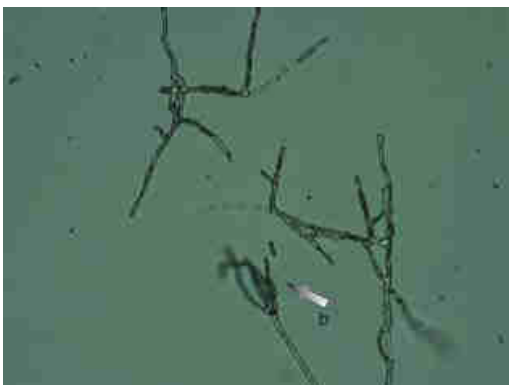

(C)

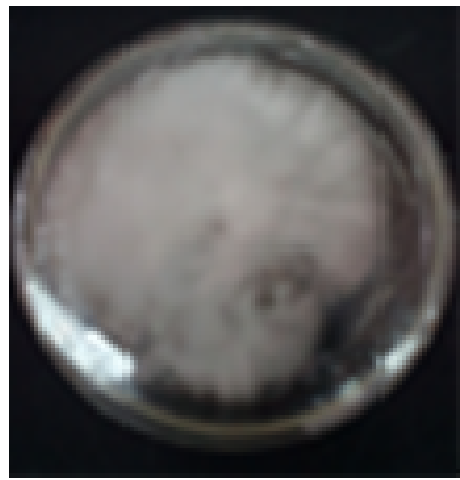

(B)

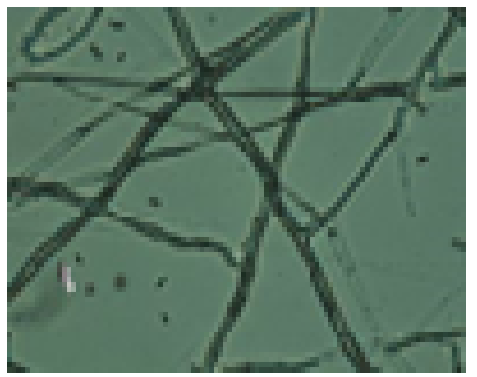

(D)

Gambar 2. Pengamatan Mikroskopis Kandidat Mikoriza pada Dendrobium sagittatum.(A). koloni mikori-za tampak atas,(B). koloni(C). (a) hifa tidak bersekat (D). Spora (b)

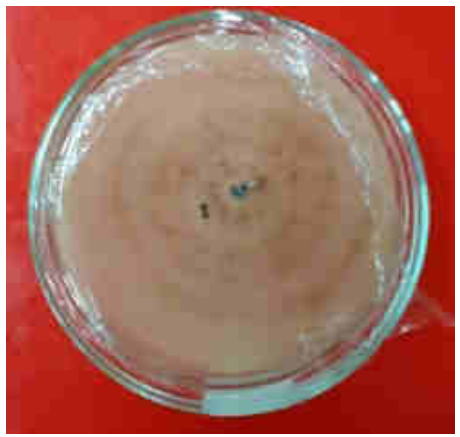

(A)

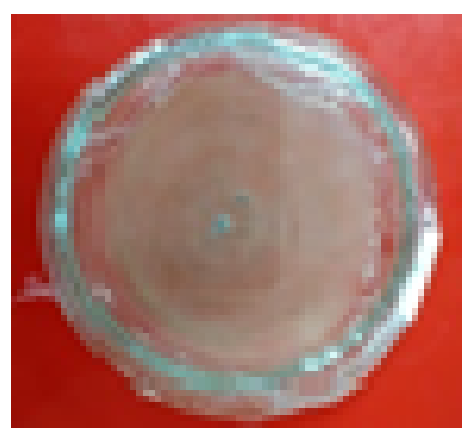

(B)

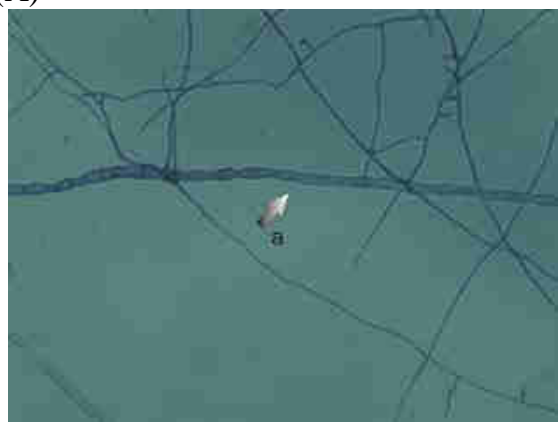

(C)

Gambar 3. Pengamatan Mikroskopis Kandidat Mikoriza pada Pholidota carnea (A) Koloni mikoriza tampak atas dan (B). Koloni mikoriza tampak bawah, (C) Hifa bersekat (a) 
Pada akar anggrek Pholidota carnea berhasil diisolasi dua kandidatmikoriza. Kandidat mikoriza 1 memiliki ciri-ciri makroskopis sebagai berikut : warna permukaan koloni putih kehijau-hijauan, permukaan flat, warna sebalik koloni putih, tekstur kapas, mempunyai zonasi dan growing zone, tidak mempunyai radial furrow, tetes eksudat dan sklerotia. Kandidat mikoriza tersebut mempunyai ciri-ciri mikroskopis hifa bersekat (Gambar 3).
Kandidat mikoriza 2 memiliki ciri-ciri makroskopis sebagai berikut : warna permukaan koloni putih, permukaan flat, warna sebalik koloni putih, tekstur kapas, tidak mempunyai zonasi dantidak mempunyai radial furrow, mempunyai growing zone, tetes eksudat dan tidak mempunyai sklerotia. Kandidat mikoriza tersebut mempunyai cici-cici mikroskopis hifa berinti satu, hifa bersekat dan terdapat spora. Kandida mikoriza tersebut masuk dalam genus Glomus (Gambar 4).

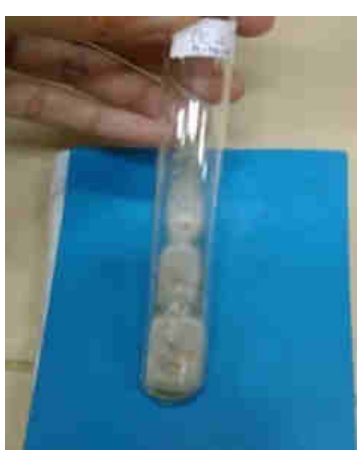

(A)

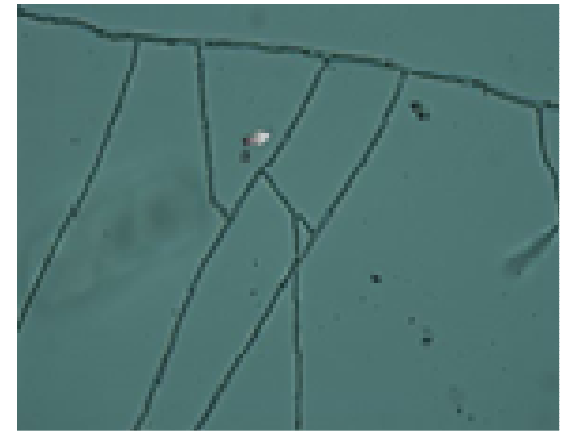

(B)

- n.

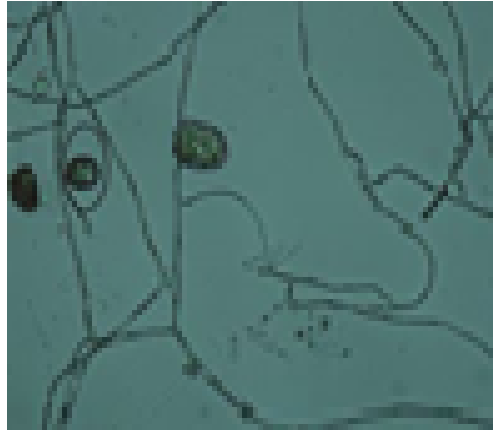

(C)

Gambar 4. Pengamatan Mikroskopis Kandidat Mikoriza pada Pholidota carnea (A). koloni mikoriza, (B). Hifa dengan inti, (C). Spora

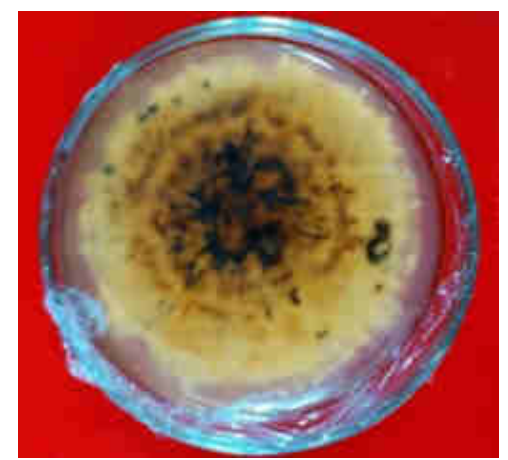

(A)

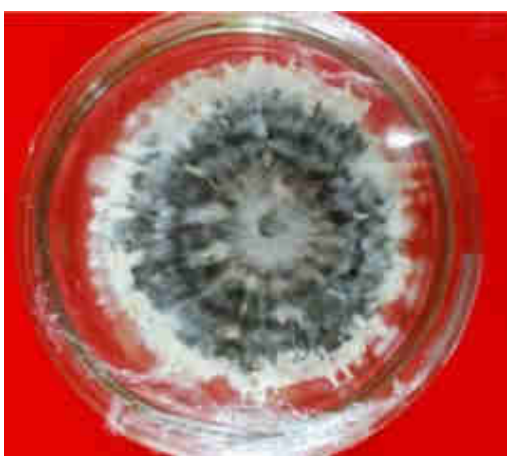

(B)

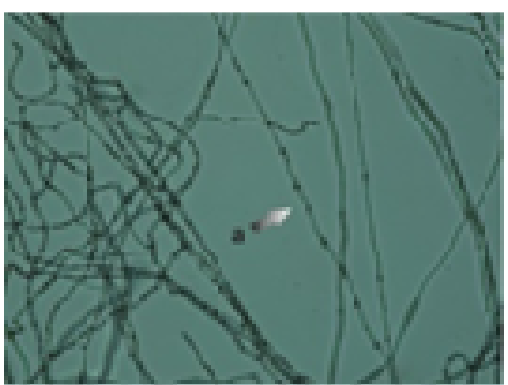

(C)

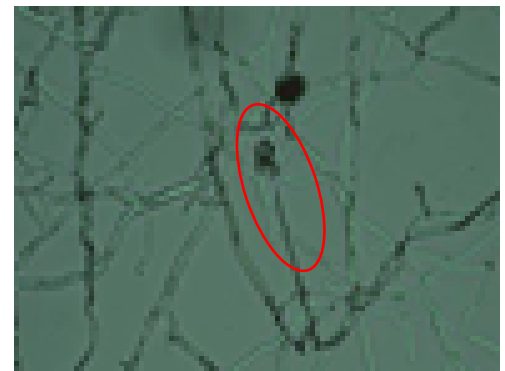

(D)

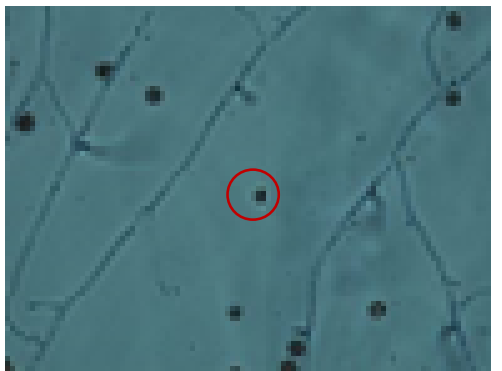

(E)

Gambar 5. Pengamatan Mikroskopis Kandidat Mikoriza pada Eria retusa. (A). koloni mikoriza tampak atas, (B). koloni mikoriza tampak bawah, (C). hifa dengan inti, (D). konidia, (E). spora 
Pada akar anggrek Eria retusa berhasil diisolasi satu kandidat mikoriza dengan ciri-ciri makroskopis sebagai berikut : warna permukaan koloni putih dan tengah abu-abu, warna sebalik koloni putuh bercak hitam, permukaan menggulung di tengah, tekstur karpet, mempunyai zonasi, mempunyai growing zone dan sklerotia, tidak mempunyai radial furrow dan tetes eksudat. Kandidat mikoriza tersebut mempunyai cici-cici mikroskopis hifa bersekat, mempunyai alat reproduksi spora, warna spora kecoklatan. Kandidat mikoriza tersebut termasuk dalam genus Glomus (Gambar 5).

Pada akar anggrek Bulbophyllum flavescens berhasil diisolasi satu kandidat mikoriza dengan ciri-ciri makroskopis sebagai berikut: warna permukaan koloni putuh bercak hitam, permukaan flat, warna sebalik koloni juga putih bercak hitam, tekstur kapas, tidak mempunyai zonasi dan radial furrow, mempunyai growing zone dan sklerotia, tidak mempunyai tetes eksudat. Kandidat mikoriza tersebut mempunyai cici-cici mikroskopis hifa bersekat, terdapat spora, memiliki alat tambahan berupa ascomata. Kandidat mikoriza tersebut termasuk dalam genus Chaetonium (Gambar 6).

Pada akar anggrek Dendrobium mutabile berhasil diisolasi satu kandidatmikoriza dengan ciri-ciri makroskopis sebagai berikut : warna permukaan koloni putih, permukaan flat, warna sebalik koloni juga putih, tekstur kapas, tidak mempunyai zonasi dan radial furrow, mempunyai growing zone, tidak mempunyai tetes eksudat dan sklerotia. Kandidat mikoriza tersebut mempunyai ciri-ciri mikroskopis hifa tidak bersekat, mempunyai spora sebagai alat reproduksi yang berwarna kecoklatan, Kandidat mikoriza tersebut termasuk dalam genus Trichoderma (Gambar 7).

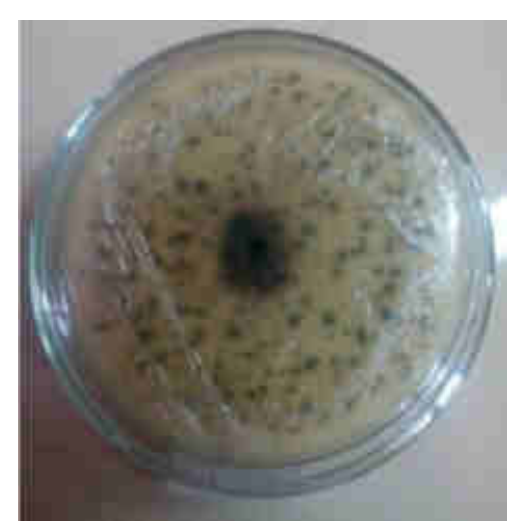

(A)

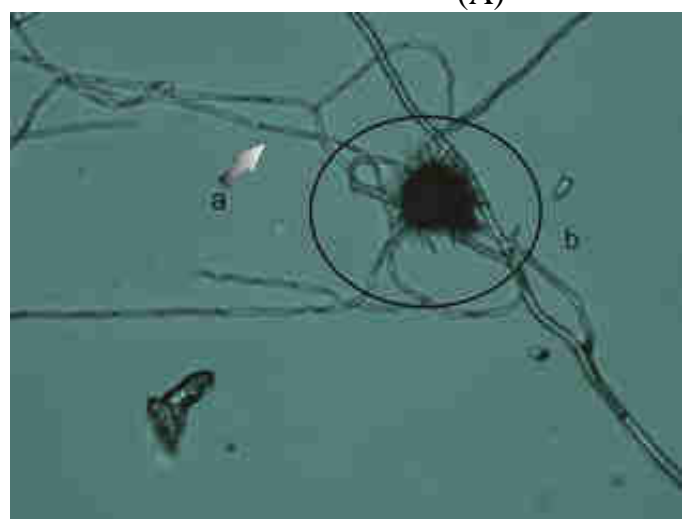

(C)

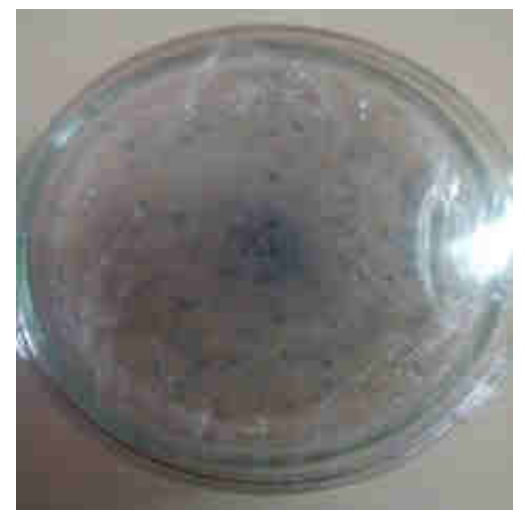

(B)

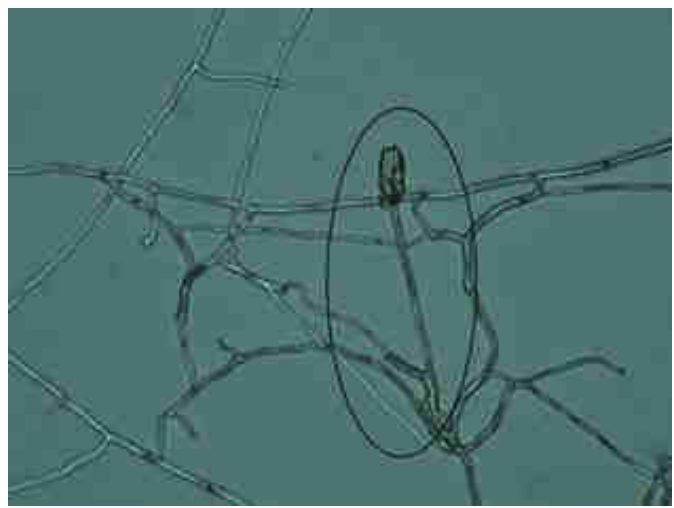

(D)

Gambar 6. Pengamatan Mikroskopis kandidat Mikoriza pada Bulbophyllum flavescens. (A) dan (B). koloni mikoriza tampak atas dan bawah. (C). hifa (a) dan ascomata (b), (D). konidia 


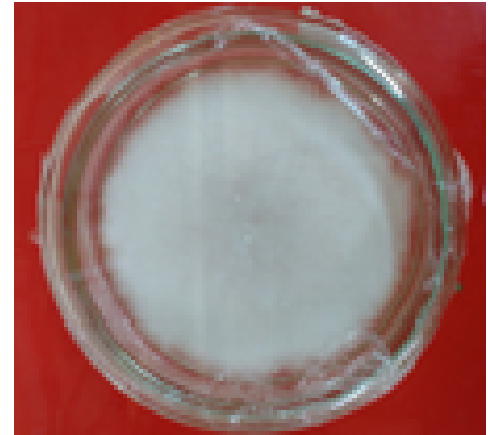

A

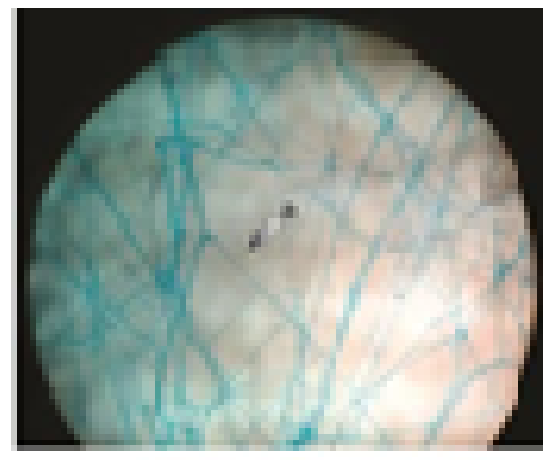

$\mathrm{C}$

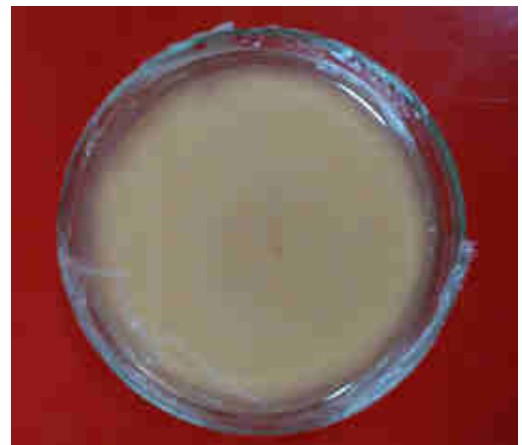

B

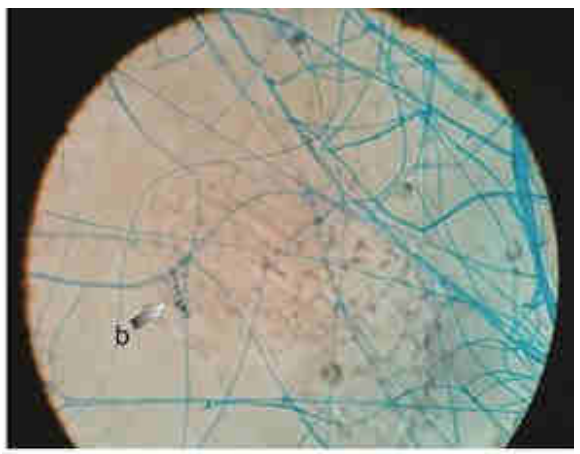

$\mathrm{D}$

Gambar 7. Pengamatan Mikroskopis Kandidat Mikoriza pada Dendrobium mutabile (A). koloni mikoriza tampak atas, (B).koloni mikoriza tampak bawah, (C). hifa tidak bersekat, (D). spora.

Proses perkecambahan biji anggrek yang terjadi karena adanya penetrasi hifa mikoriza menembus testa, dan menginvasi ke embrio hingga menginfeksi ke sel korteks membentuk massa yang bertautan (hifa yang menggulung) disebut peloton. Peloton merupakan karakter khusus pada mikoriza anggrek. Peloton ini akan dimanfaatkan oleh anggrek dan merupakan sumber karbohidrat yang akan diserap dan kemudian akan hancur dan hilang. Hasil pengamatan mikroskopis penampang melintang akar anggrek dan keberadaan peloton mikoriza pada akar anggrek dapat dilihat sebagai berikut :

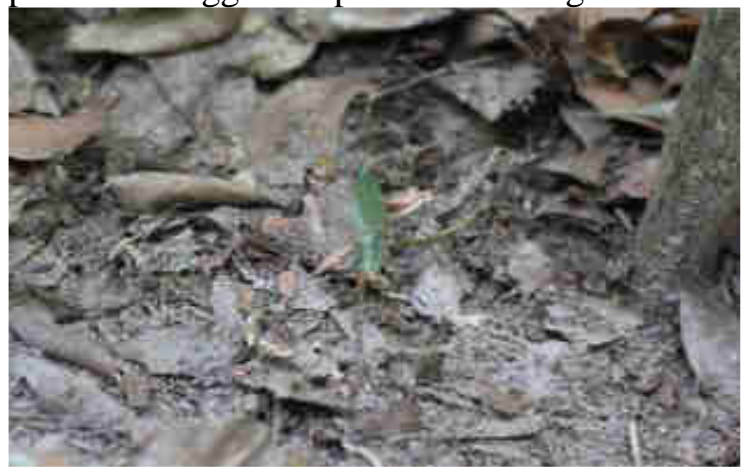

Zeuxine petakinensi
(Anggrek ini hanya ada satu, sehingga tidak diambil untuk sampel yang akan diamati mikoriza)

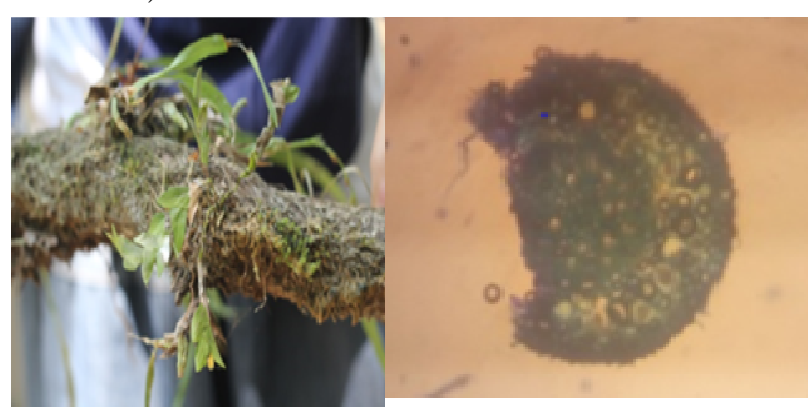

Dendrobium sagittatum

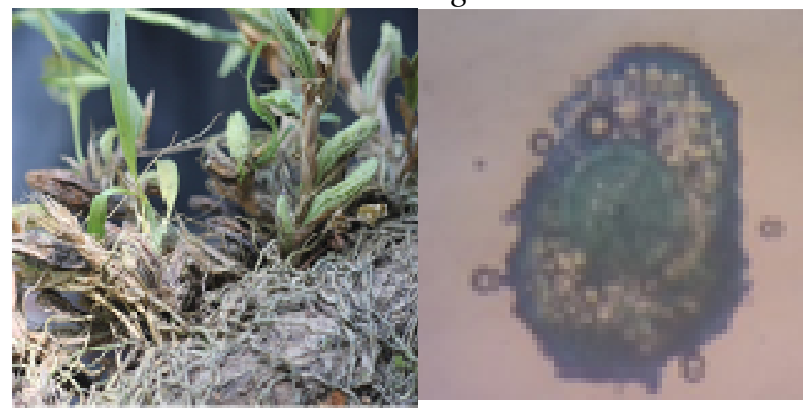

Bulbophyllum flavescens 

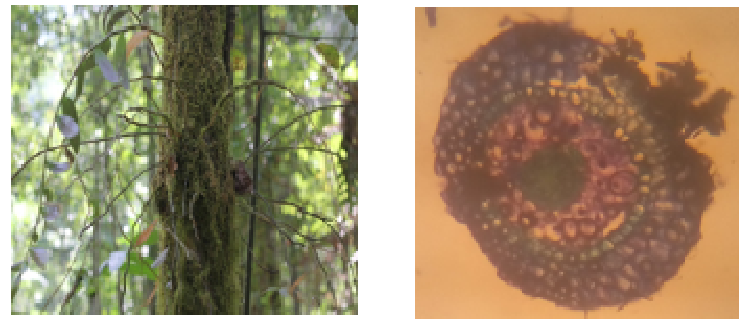

Dendrobium mutabile
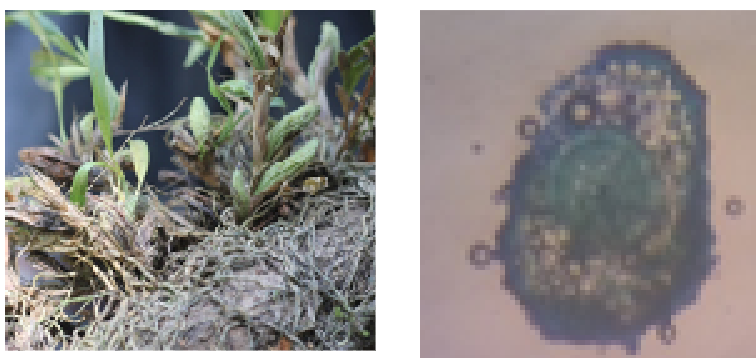

Eria retusa

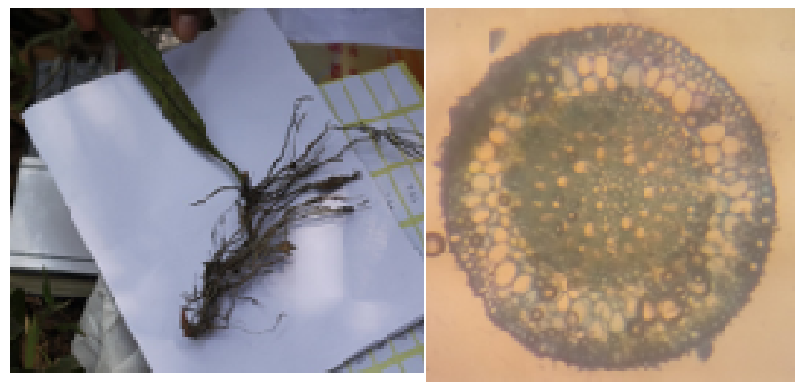

Pholidota carnea

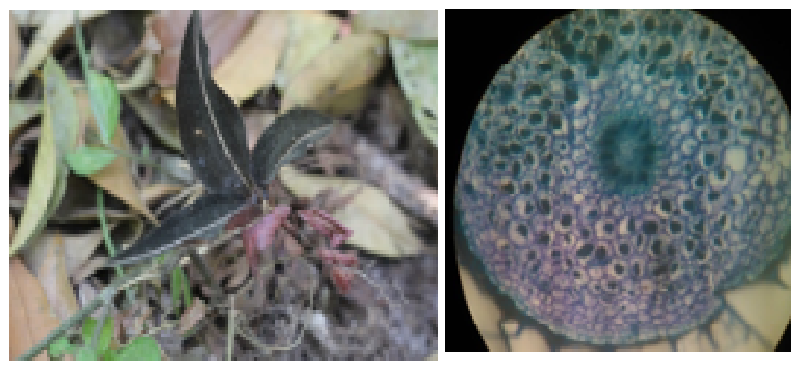

Rhomboda veluntina

Dari hasil pengamatan keberadaan peloton mikoriza pada akar anggrek terlihat bahwa tidak semua sel-sel akar terdapat mikoriza. Keberadaan mikoriza pada akar anggrek berbeda antara tanaman satu dengan lainnya. Hal ini tergantung struktur anatomi dari masing-masing anggrek dan kemungkinan azosiasi dengan jenis cendawan yang dapat bersimbiose. Diameter akar anggrek yang kecil dan memudahkan cendawan untuk memenuhi sel-sel akar yang diinvasi, sehingga pada diameter akar yang kecil lebih banyak dipenuhi peloton mikoriza dibandingkan diameter yang lebih besar ukurannya.

\section{Simpulan}

Tanaman anggrek spesies yang didapat adalah,Zeuxine petakinensis, Dendrobium sagittatum, Bulbophyllum chaetonium, Dendrobium mutabile, Eria retusa, Eria oblitterata, Pholidota carnea, Rhomboda velutina. Beberapa anggrek spesies di hutan tersebut dalam keadaan dorman sehingga tidak dapat diidentifikasi.

Keberadaan mikoriza hasil pengamatan mikroskopis menunjukkan bahwa pada umumnya akar anggrek spesies berasosiasi simbiose dengan mikoriza yang masing-masing menunjukkan jenis fungi yang berbeda. Fungi yang dapat didentifikasi diantaranya termasuk dalam jenis Rhizoctonia, Glomus, Chaetonium, Scopulariopsis dan Trichoderma.

\section{Ucapan Terima Kasih}

Ucapan terima kasih diberikan kepada Fakultas Matematika dan Ilmu Pengetahuan Alam Universitas Negeri Yogyakarta sebagai penyandang dana penelitian ini.

\section{Pustaka}

[1] Koay, S. H., 1990, A Review of Flowering in Orchids, Proceedings of The Seventh Asian Orchids Conggress.

[2] Arditti, J., 1992, Fundamentals of Orchid Biology, John Wiley \& Sons, New York.

[3] Withner, C. L., 1974, The Orchid, Scientifics Studies, John Wiley \& Sons, New York

[4] Hunt, P. F. 1984, Orchids, Marshall, Cavendish Books Limited, London

[5] Agrios, G. N., 1978, Plant Pathology, Academic Press, New York

[6] Anonim, 1993, Menyilang Anggrek, Penebar Swadaya, Seri Pertanian.

[7] Englander, L., 1982, Endomycorrhizae by Septate Fungi, dalam Schenck, N. C., 1982, The American Phytopathological Society, St Paul Minnesota.

[8] Arifin, H. S. dan B. Sulistyantara, 1990, Anggrek Vanda. Penebar Swadaya, Seri Pertanian 
[9] Athipunyakom, P., L. Manoch, dan C. Piluek, 2004, Isolation and Identification of Mycorrhizal Jamur from Eleven Terrestrial Orchids. Kasetsart Journal (Nat.Sci.) 38

[10] Gunadi, T., 1979, Sifat-sifat Umum Tanaman Induk dengan Tinjauan Khusus Vanda dan Dendrobium, dalam Anggrek Indonesia, Perhimpunan Anggrek Indonesia cabang Bandung

[11] Irawati dan Saroso, 1980, Penggalian Potensi Anggrek Jenis Asli, Media Anggrek, No 13, Tahun III : Bulan Maret - April 1980

[12] Santosa, A. S. 1980, Cara Memperba-nyak Spesies pada Habitatnya, Media Anggrek No 15 - 16, Tahun III : Juli - Desember 1980
[13] Soeryowinoto, S. M., 1974, Merawat Anggrek, Penerbitan Yayasan Kanisius

[14] Soemartono, Nasrullah dan H. Hartiko, 1992, Genetika Kuantitatif dan Bioteknologi Tanaman, PAU Biotekno-logi, UGM

[15] Soelistijono, Dwi Susilo U., dan Achmadi P., Karakterisasi Isolat Rhizoctonia Mikoriza pada Anggrek Phalaenopsis amabilis. Jurnal Agrineca Vol 12 (2)

[16] Sumarni, 1989, Dendrobium spectabile, Anggrek Kribo dari Irian, Trubus No 233, Th XX : 153, April 1989 